\title{
ASU Student Sets Up Microwave Processing Laboratory in South Africa \\ Douglas Thompson
}

I first met Ngcali Tile of the University of Western Cape (UWC) when he visited my department at Arizona State University (ASU) — through a cooperative grant-to work on his master's project in materials research. Ngcali was researching a method of silicon exfoliation and layer transfer called "ion-cut." In ion-cut silicon exfoliation, a thin layer of silicon can be transferred to a heterogeneous substrate. Ion-cut research is most associated as an alternative means of producing silicon-on-insulator (SOI) substrates for semiconductor processing. In South Africa, Ngcali had studied the physics of ion-cut silicon exfoliation and ran some experiments, but he needed the resources available at ASU in order to help characterize ion-cut samples.

I was chosen by my professors involved in the international collaboration to work with Ngcali because I had already been working on ion-cut research for my doctorate project. At ASU, my efforts in ion-cut research resulted in several ion-cut sample characterization techniques, a wafer-bonding laboratory to help fabricate ion-cut samples, a microwave furnace for thermal activation of ion-cut exfoliation, and publication of my findings in journals such as Applied Physics Letters and Journal of Applied Physics.

After processing and characterizing ion-cut samples at ASU, Ngcali returned to South Africa to continue his research, where his professor decided that their laboratory should have a microwave furnace with which Ngcali could recreate the ioncut processing he had done at ASU. Microwave processing of ion-cut materials was attractive because the capital costs were small, and the results of processing were as good as or better than current ion-cut technologies. Our professors obtained grants from the U.S. National Science Foundation and South Africa's National Research Foundation, which funded my travel to UWC to help set up their laboratory in February 2007.

My travel time from Phoenix to Cape Town was just under 46 hours, including three flights and a 10-hour layover in Frankfurt, Germany. By the time I arrived in South Africa, I definitely had a feel for the distance separating our continents.
The facilities in SA are more decentralized than in the states, so I had to plan well in advance for my stay. For example, I knew I would need a microwave leak detector in SA in order to ensure the modifications I make to a microwave do not result in an unsafe condition. I had to purchase a microwave leak detector in the states and place the detector in my baggage because the acquisition of a leak detector in SA was too difficult to pursue with the limited time of my stay.

When I arrived in Cape Town, I met with Ken Strieb, a postdoctoral appointee at UWC, who was assigned with acquainting me with my surroundings, facilitating my stay, and helping Ngcali and me in our research collaboration. After our initial greeting, Ken and I immediately traveled to iThemba Labs (Faure site), where I toured several laboratories and a machine shop made available to students at UWC. iThemba Labs make up a national research facility in SA that collaborates with universities on select projects.

I wrote a small proposal for iThemba Labs in order to request machine shop time and a technician's help. On approval of the proposal, Ken and I traveled to iThemba Labs to machine the needed parts for insertion of an infrared sensor into the microwave unit. Ken and I installed the infrared sensor and some hardware for a microwave choke tube into UWC's microwave furnace. While in the states, preparing for my trip to SA, I found that a second iThemba Lab in Johannesburg, SA had an ion implanter capable of implanting the species needed to make ion-cut samples. This implanter was housed in iThemba Labs, but the principle investigator funding the machine's use works as a professor at Witwatersrand University in Johannesburg. I was elated to find out about this machine because the creation of an ion implant process in SA would be most beneficial at UWC.

After discussing the specifics of the implanter I determined that the implanter was very similar to one I had used to implant hydrogen and boron into silicon when I visited the materials science division of Los Alamos National Laboratory in 2003. This information convinced me that ion implant was possible in SA, and I was intent on developing an ion implant process for ion-cut research at the university. If successful, Ncgali would have more samples for research while simultaneously creating a means to fabricate samples in the future.

At Johannesburg, Ncgali and I worked on the ion implanter. After overcoming issues with introducing a new process to an established machine, we determined the machine was in a state as to start sample processing, so Ngcali and I started implanting hydrogen and boron into silicon to make ion-cut samples. Four days later, we finished sample processing with our new South African-made ion-cut samples.

Ngcali and I returned to Cape Town with our new ion-implanted samples and an implant process designed for use on the Varion/Extrion Division ion implanter at iThemba Labs (Gauteng). I presented the samples along with specifics of the implant process for future collaboration of UWC with iThemba Labs. During my remaining days in SA, I helped Ngcali finalize an article about his research.

I am very happy with my research collaboration in SA. To say that the people at UWC were very helpful, friendly, and accommodating would not do them justice. They went out of their way to ensure that my stay was enjoyable as well as successful. The students I housed with were as friendly and helpful as the university 


\section{INTERFACES}

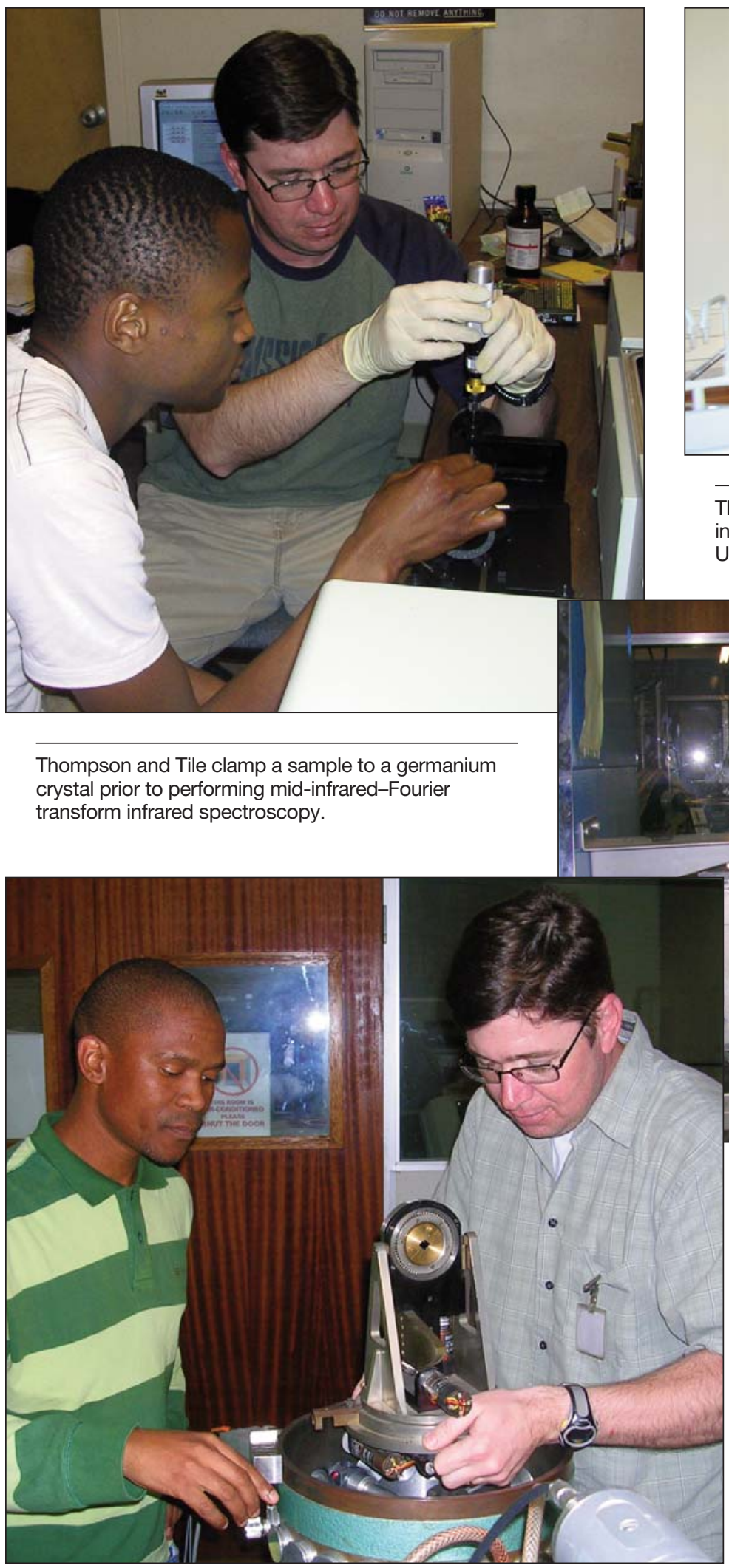

An iThemba Labs ion beam analyst Phillip Sechogela (left) and Thompson insert a sample mounted to a three-axis goniometer into an RBS analysis chamber.

Thompson and Tile clamp a sample to a germanium crystal prior to performing mid-infrared-Fourier transform infrared spectroscopy.

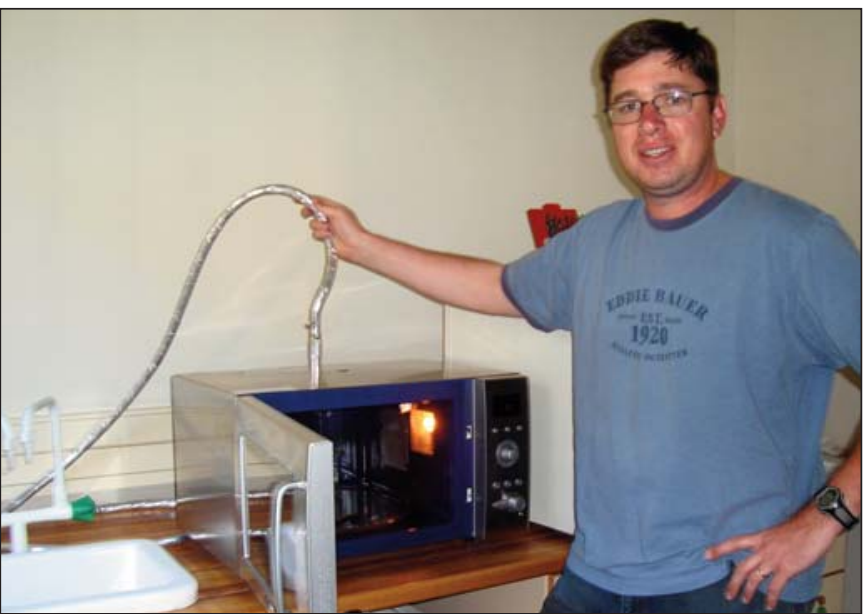

Thompson holds a gas purge line used to cool an installed infrared sensor after modification of a microwave furnace at the University of Western Cape.
Thompson fills a liquid nitrogen reservoir on the Varion/Extrion ion implanter at iThemba Labs (Gauteng). Liquid nitrogen is used to cool samples during implant

staff. iThemba Labs staff and researchers were very accommodating and incremental in my research success in SA. I hope my success opens the door for more U.S. collaboration with South African universities in the future.

\section{Acknowledgments}

I would like to give thanks to Prof. Daniel Adams, Ngcali Tile, Angela Adams, and Ken Strieb at the University of Western Cape; Chris Theron at iThemba Labs (Faure); Isaac Machi at iThemba Labs (Gauteng); my professors at Arizona State University, Terry Alford and James Mayer; and all others whom helped me during my stay in South Africa for their patience and assistance in my research efforts. 